MATEC Web of Conferences 13, 03003 (2014)

DOI: $10.1051 /$ matecconf/ 20141303003

(C) Owned by the authors, published by EDP Sciences, 2014

\title{
Vibration Attenuation of Plate Using Multiple Vibration Absorbers
}

\author{
Izzuddin Zaman ${ }^{1,2}$, a, Muhammad Mohamed Salleh ${ }^{1}$, Maznan Ismon ${ }^{1}$, Bukhari Manshoor ${ }^{1}$, Amir \\ Khalid $^{1}$, Mohd Shahrir Mohd Sani ${ }^{3}$ and Sherif Araby ${ }^{4}$ \\ ${ }^{1}$ Faculty of Mechanical and Manufacturing Engineering, ${ }^{2}$ Stuctural Integrity and Monitoring Research \\ Group, Universiti Tun Hussein Onn Malaysia, 86400 Batu Pahat, Johor, Malaysia \\ ${ }^{3}$ Faculty of Mechanical Engineering, Universiti Malaysia Pahang, 26600 Pekan, Pahang, Malaysia \\ ${ }^{4}$ School of Advanced Manufacturing Engineering, University of South Australia, SA 5095, Australia
}

\begin{abstract}
Vibrations are undesired phenomenon and it can cause harm, distress and unsettling influence to the systems or structures, for example, aircraft, automobile, machinery and building. One of the approach to limit this vibration by introducing passive vibration absorber attached to the structure. In this paper, the adequacy of utilizing passive vibration absorbers are investigated. The vibration absorber system is designed to minimize the vibration of a thin plate fixed along edges. The plate's vibration characteristics, such as, natural frequency and mode shape are determined using three techniques: theoretical equations, finite element (FE) analysis and experiment. The results demonstrate that the first four natural frequencies of fixed-fixed ends plate are 48, 121, 193 and $242 \mathrm{~Hz}$, and these results are corroborated well with theoretical, FE simulation and experiment. The experiment work is further carried out with attached single and multiple vibration absorbers onto plate by tuning the absorber's frequency to match with the excitation frequency. The outcomes depict that multiple vibration absorbers are more viable in lessening the global structural vibration.
\end{abstract}

\section{Introduction}

Excessive vibration in engineering systems are generally undesirable, and therefore avoided for the purpose of safety and solace. On top of that, exposure to vibration for a long time span can be harmful as it causes disease and muscular-skeletal pain [1-3]. Therefore, there are need for vibration control with the adequate approaches in order to avert all these awful effects.

Generally, the standard solution to solve this vibration issue is to redesign and modify the system, which is done by combination of increasing the thickness of the panel wall, stiffening the structure, and adding damping [4,5]. Previously, numerous studies have been devoted to develop a feasible method to reduce vibration that generated by machines [6,7]. These include: (i) modifying the framework, so the natural frequency does not coincide with the operating speed, (ii) apply damping to counteract large response, (iii) installing isolating devices between adjacent sub-systems and (iv) adding discrete masses into equipment to reduce the response and retain vibration.

In spite of these studies and knowledge gained thus far, it has not yet reached a circumstance where a person able to find a vibration control method to fit all vibration situations. In fact, the first

a izzuddin@uthm.edu.my

This is an Open Access article distributed under the terms of the Creative Commons Attribution License 2.0, which permits unrestricted use, distribution, and reproduction in any medium, provided the original work is properly cited. 
three aforementioned methods are hard to be implemented and not really effective due to design complexity, costly, and unfeasible at lower frequency. The latter approach using discrete masses or known as passive vibration absorbers, however, are more sound because they do not contribute significant additional vibration energy to the structure, besides demonstrated to yield substantial attenuation in structural vibration [8-10]. Nevertheless, it produces drawbacks such as the obvious weight increase, and improperly placement and frequency tuning of vibration absorber may result in large increase of vibration level $[9,10]$.

The idea of passive vibration absorber emerges due to a common vibration issue existed in engineering structural applications. The concept of a vibration absorber as illustrated in Fig. 1, comprising of spring, mass and damping elements, which has the capacity to stifle the vibration of the host structure. Moreover, a current vibration absorber only adapt to one single excitation frequency and is not capable to reduce the global structural vibration comprehensively [11]. Due to that, multiple passive vibration absorbers are obliged in order to accomplish this objectives.

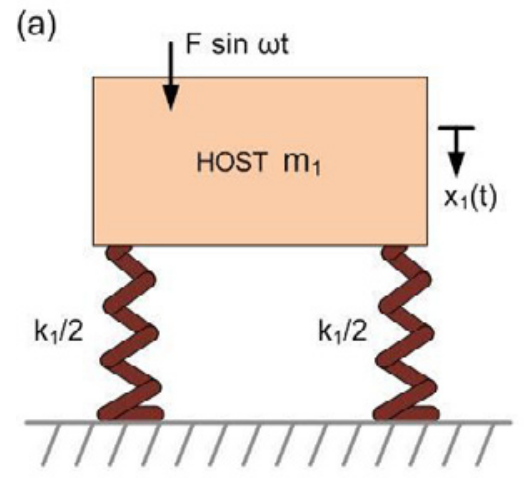

Fig. 1. (a) Before and (b) After adding vibration absorber

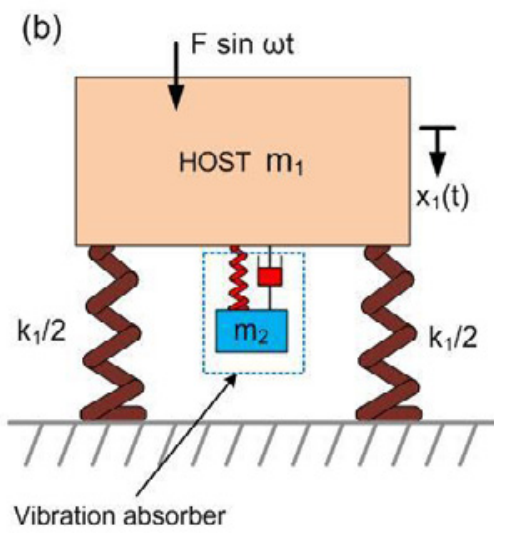

In this study, a new control strategy using multiple passive vibration absorbers attached to a flexible thin plate is being researched, in such, to counter the vibrating force across the structure globally. Three techniques are implemented in the study to establish vibration characteristics of plate: (1) mathematical equation analysis by Matlab, (2) finite element analysis by Solidworks and (3) experimental vibration testing, in which afterward a further investigation is adhered with adding passive vibration absorbers.

\section{Mathematical Equations}

\subsection{Vibration absorber}

The equation of motion of host structure in the vertical direction is shown in Eq. 1 where $x=x(t)$ is a displacement and $F \sin \omega t$ is the disturbance applied to the host structure. It is a necessary to come out with a design, in which the displacement of primary system should be as minimum as possible in the steady state condition [7].

$$
\left[\begin{array}{cc}
m_{1} & 0 \\
0 & m_{2}
\end{array}\right]\left[\begin{array}{l}
\ddot{x}_{1} \\
\ddot{x}_{2}
\end{array}\right]+\left[\begin{array}{cc}
k_{1} & -k_{a} \\
-k_{1} & k_{a}
\end{array}\right]\left[\begin{array}{l}
x_{1} \\
x_{2}
\end{array}\right]=\left[\begin{array}{c}
F \sin \omega t \\
0
\end{array}\right]
$$

The ratio absorber mass to primary mass:

$$
\mu=\frac{m_{2}}{m_{1}}
$$


Upon examining the mass ratio $\mu$, the matters concerning of avoiding resonance in absorber of the driving frequency cases can be measured. This condition can be defined as the ratio of absorber mass to the primary mass shown in Eq. 2.

\subsection{Plate}

Structures such as plate are used in many engineering applications. Knowledge of the relationship between physical structural characteristics of plate and modal parameters can provide considerable great insight into the methods to reduce undesirable structural responses [12]. Fig. 2 shows a fixedfixed ends plate subjected to point load $F$. The plate has a uniform thickness, $h$. The equation motion of plate can be written in Eq. 3, where $\rho$ is density and $I$ is the area moment of inertia which defined in Eq. 4.

Fig. 2. Fixed-fixed ends plate

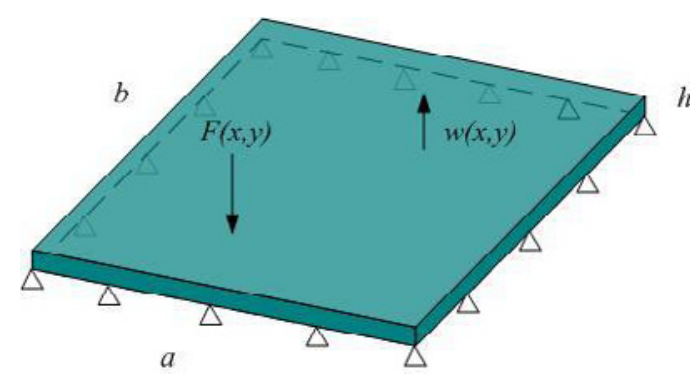

$$
\begin{gathered}
E I\left(\frac{\partial^{4} \omega}{\partial x^{4}}+2 \frac{\partial^{2} \omega}{\partial x^{2} \partial y^{2}}+\frac{\partial^{4} \omega}{\partial y^{4}}\right)+\rho h \frac{\partial^{2} \omega}{\partial t^{2}}=-F(x, y, t) \\
I=\frac{h^{3}}{12\left(1-v^{2}\right)}
\end{gathered}
$$

\section{Methodology}

\subsection{Finite Element Analysis (FEA)}

Two models were simulated and analysed using Solidworkds ${ }^{\circledR}$ which are fixed-fixed end plate and passive vibration absorber, in order to determine the natural frequencies and mode shapes of the systems. The dimension of plate and vibration absorber to be studied are $450 \times 450 \times 2 \mathrm{~mm}$ and $280 \mathrm{x}$ $30 \times 30 \mathrm{~mm}$, respectively. Material employed for both plate and absorber is mild steel. Fig. 3 shows the meshed models of plate and vibration absorber. Both of the models were meshed using solidhexagonal 8-nodes.

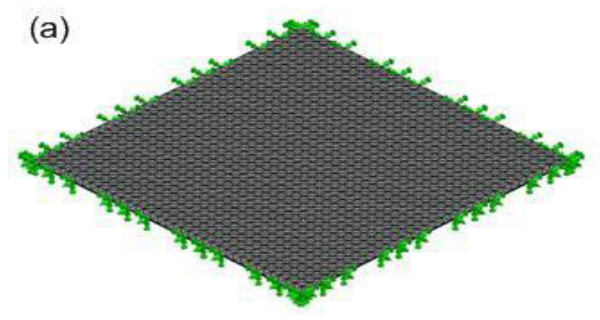

(b)

Fig. 3. FE meshed model of (a) plate, and (b) vibration absorber

\subsection{Vibration testing}

Similar to our previous study in ref. [4], the experiment was conducted using DEWE Analyzer. The vibration response of plate is measured at 16 different points simultaneously. In initial stage, this method was employed to validate the theoretical equations and finite element model by determining 
the natural frequencies of plate. Later, an in-depth investigation is carried out to determine the dynamic response of plate, with and without attached vibration absorber. The attachment of vibration absorber onto plate was implemented using screw and nut as depicted in Fig. 4.

\section{Result and Discussion}

In the mathematical modelling of plate, the analysis was performed and plotted using Matlab®. Table 1 tabulates the natural frequencies of fixed-fixed ends plate obtained from mathematical modelling, finite element analysis and experiment. The results showed that all these approaches corroborated well, although there is small discrepancy in the experimental result due to error and noise measured during testing.

Fig. 4. Vibration amplitude of plate against frequency

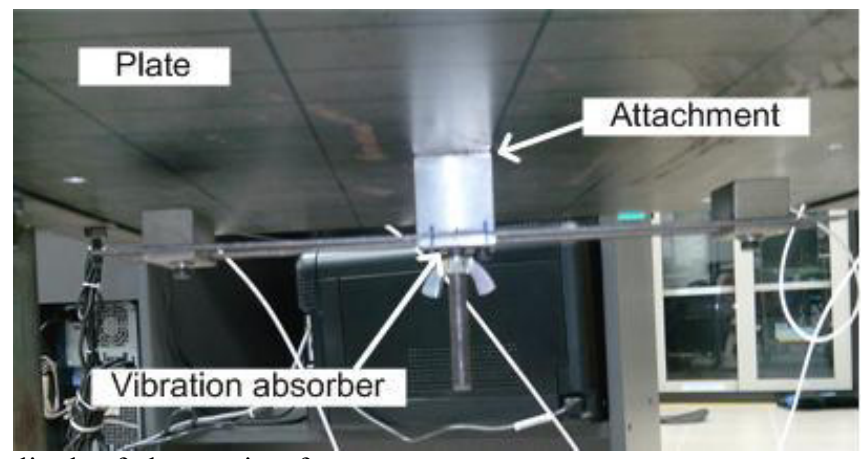

Table 1. Natural frequencies of plate in unit $\mathrm{Hz}$

\begin{tabular}{cccc}
\hline Mode & Matlab ${ }^{\circledR}$ & Solidworks ${ }^{\circledR}$ & Experiment \\
\hline 1 & 48 & 48 & 41 \\
2 & 121 & 121 & 122 \\
3 & 193 & 194 & 163 \\
4 & 242 & 242 & -
\end{tabular}

Fig. 5 shows the plot of vibration response of plate against frequency, which obtained from vibration test. The frequency range of studied was set within $0-200 \mathrm{~Hz}$. The peaks represent the natural frequency of fixed-fixed ends plate as tabulated in Table 1. Obviously, with absorber attachment onto plate, the vibration amplitude of plate (measured in unit of g-rms) was found decreases. Later, it was noticed that this amplitude reduced significantly through out the plate and the frequency modes, when dual absorbers were attached onto plate. The average global vibration reduction obtained with dual absorbers attachment is about $45 \%$. In this case, the absorbers attachment was fixed at points 6 and 10 (refer Fig. 2 in ref. [12]). 


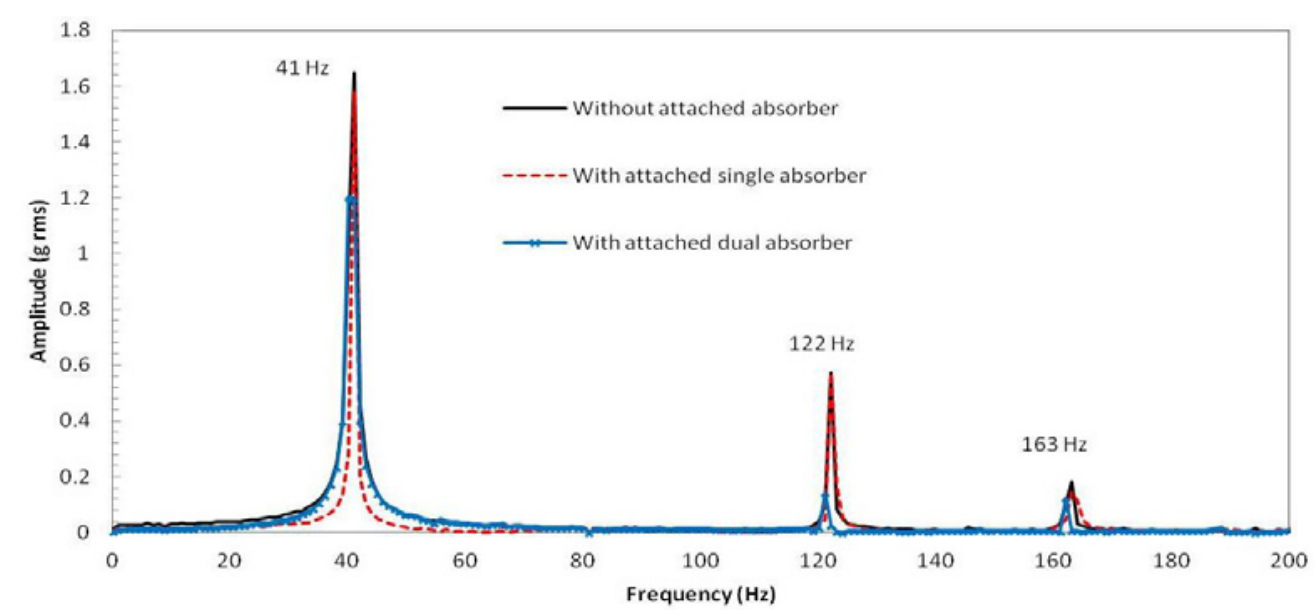

Fig. 5. Vibration amplitude of plate against frequency

\section{Conclusion}

The analytical equation, finite element simulation and experimental approaches have been implemented successfully to investigate the vibration attenuation of fixed-fixed ends plate by employing multiple passive vibration absorber. The result of natural frequencies corroborated well with simulation and analytical equations, though dissimilarity was found in third frequency mode of experiment. When the plate was attached with vibration absorber, the resonance amplitudes was found reduce. Dual absorbers attachment shows better result in reducing the global resonance vibration of entire plate's surface. However, this result is expected to improve considerably if: (1) the absorber's frequency is tuned accurately to plate's frequency, and (2) the location of absorber is considered in the study.

\section{Acknowledgement}

IZ thanks Universiti Tun Hussein Onn Malaysia for the support under Short Term Grant, vote 1332 and provides facilities for this research.

\section{References}

[1] S.H. Shin, J.G. Ih, T. Hashimoto, S. Hatano, Sound quality evaluation of the booming sensation for passenger cars, Appl. Acoustics 70, pp. 309-320, (2009).

[2] M.S. Qatu, M.K. Abdelhamid, J. Pang, G. Sheng, Overview of automotive noise and vibration, Int J. of Veh. Noise and Vib. 5, pp. 135, (2009).

[3] C. Bosco, M. Cardinale, R. Colli, J. Tihanyi, S.P. von Duvillard, A. Viru, The influence of whole body vibration on the mechanical behavior of skeletal muscle, Clinical Physio. 19, pp. 183-187, (1999).

[4] I. Zaman, A. Khalid, B. Manshoor, S. Araby, The effects of bolted joints on dynamic response of structures, IOP Conf. Series: Mat. Sci. and Eng. 50, 012018, (2013).

[5] I. Z. Bujang, M.K. Awang, A.E. Ismail. Study on the dynamic behavior of coir fiber reinforced composites, Reg. Conf. on Eng. Maths, Mech, Manufact. \& Architecture (EM3ARC), (2007).

[6] J. H. Koo, M. Ahmadian, M. Setareh, T.M. Murray, In search of suitable control methods for semi-active tuned vibration absorbers, J. of Vib. Contr. 10, (2004). 
[7] I. Zaman, B. Manshoor, A. Khalid, S. Araby, M.I. Ghazali, Vibration characteristics of composite plate embedded with shape memory alloy at elevated temperature, Appl. Mech and Mat. 393, pp. 655-660, (2013).

[8] W. O. Wong, W.O. Cheung, Optimal design of a damped dynamic vibration absorber for vibration control of structure excited by ground motion, Eng. Struc. 30, (2008).

[9] M. J. Brennan, Some recent developments in adaptive tuned vibration absorbers/neutraliser, Shock and Vib. 13, (2006).

[10] J. Q. Sun, M. R. Jolly, M. A. Norris, Passive, adaptive and active tuned vibration absorbers - $a$ survey, Trans. of the American Soc. of Mech. Engrs. 117, pp. 234-242, (1995).

[11] R.I. Wright, M.R.F. Kidner, Vibration absorbers: a review of applications in interior noise control of propeller aircraft, J of Vib. and Contr. 10, pp. 1221-1237, (2004).

[12] I. Zaman, K.A. Kamaruddin, M.T. Nordin, Identification of structural defects using modal technology, Int. Conf. on Construct. Building Tech., (2007). 